\title{
VALORISATION DES SOUS-PRODUITS DE LA PÊCHE POUR L'ALIMENTATION DES POULETS
}

\section{ENHANCING FISHERY BY-PRODUCTS BY INTRODUCING THEM INTO CHICKEN FEED}

\author{
VALORIZACIÓN DE SUBPRODUCTOS DE LA PESCA \\ PARA LA ALIMENTACIÓN DE POLLOS
}

\author{
C.E. Raheriniaina ${ }^{*}$ Z. Randriamahatody ${ }^{2}$ E. Fanjara ${ }^{1}$ E.M. Fitahia ${ }^{1}$ D. Andrianasolo ${ }^{1}$ \\ H.I. Hantanirina ${ }^{3}$ L. Razanamparany ${ }^{4}$
}

\begin{abstract}
Mots-clés : Volaille - Sous-produit - Alimentation des animaux - Poulpe - Calmar - Protéine animale Performance animale.
\end{abstract}

Keywords: Poultry - By-product - Feed formulation - Animal feeding - Octopus - Squid - Animal protein - Animal performance.

Palabras clave: Ave de corral - Subproducto - Alimentación de los animales - Pulpo - Calamar - Proteína de origen animal - Desempeño animal.

e traitement, le conditionnement et la transformation des _ produits de la pêche génèrent une quantité importante de sous-produits de la pêche (SPP). Ces derniers sont constitués notamment par des têtes, des viscères, de la peau, des écailles, des arêtes, des queues, etc. A défaut d'une stratégie de valorisation, ils sont jetés et deviennent alors source de pollution, ce qui pose un problème environnemental et sanitaire. Face à cette contrainte, l'équipe du laboratoire Valoremar de I'Institut halieutique et des sciences marines a mis en ouvre un programme de recherche étudiant la possibilité de valoriser les SPP en alimentation avicole. L'étude a été initiée en raison de la présence probable de molécules valorisables dans les SPP, notamment des protéines. Nous avons ainsi constitué la base protéique de l'alimentation des poulets avec de la farine de SPP (1), mélangée à d'autres ingrédients disponibles, sources de matières énergétiques, minéraux, vitamines...

Au laboratoire, la farine a été préparée avec des sous-produits de poulpe et de calmar fournis par une société de pêche basée à Toliara, suivant le procédé de transformation rapporté par le département de la pêche de l'Organisation des Nations unies pour l'alimentation et l'agriculture (2). II s'agit d'un traitement thermique visant à séparer les fractions solides, huileuses et

1. Institut halieutique et des sciences marines, université de Toliara, BP 141 , route du Port, avenue de France, Toliara 601, Madagascar.

2. Centre national de recherches sur l'environnement, 39 rue Rasamimanana Fiadanana, BP 1739, Antananarivo 101, Madagascar.

3. Ecole supérieure des sciences agronomiques, université d'Antananarivo, Antananarivo, Madagascar.

4. Faculté des sciences, université d'Antananarivo, Antananarivo, Madagascar.

* Auteur pour la correspondance

E-mail : raheriniaina.christian@gmail.com aqueuses. La farine de SPP a été produite à partir des fractions solides et a permis d'élaborer les rations expérimentales (1) (tableau I). L'introduction des farines de poulpe et de calamar s'est faite en remplaçant 50 p. 100 (lots C50 et P50) ou 100 p. 100 (lots C100 et P100) du tourteau d'arachide dans un aliment à base de son de maïs et de son de riz.

Les poulets étaient des mâles de race locale d'un poids moyen de $250 \mathrm{~g}$ à l'entrée et de $485 \mathrm{~g}$ en moyenne après la quarantaine. Le test a été réalisé en station sur cinq lots de 25 poulets dont un lot témoin. Les poulets ont été élevés dans les mêmes conditions d'habitat et ont reçu leur nourriture respective de 120 g par tête par jour, en deux distributions (matin et après-midi). La croissance des animaux a été suivie jusqu'à 12 semaines. Un autre essai, utilisant des régimes comparables, a porté sur le transfert des techniques aux bénéficiaires. Il a été réalisé dans une ferme pilote et conduit par I'association Ezaka de Saint Augustin, district de Toliara II, région Atsimo Andrefana.

Le rendement de la production de farines de SPP a été de 15 p. 100. Les farines produites étaient très riches en protéines,

\section{Tableau I}

Composition des aliments expérimentaux dans la ration de poulets tests

\begin{tabular}{lccccc} 
Matière première & \multicolumn{5}{c}{ Ration* (g/kg) } \\
\cline { 2 - 6 } & $\begin{array}{c}\text { Lot } \\
\text { témoin }\end{array}$ & $\begin{array}{c}\text { Lot } \\
\text { P50 }\end{array}$ & $\begin{array}{c}\text { Lot } \\
\text { C50 }\end{array}$ & $\begin{array}{c}\text { Lot } \\
\text { P100 }\end{array}$ & $\begin{array}{c}\text { Lot } \\
\text { C100 }\end{array}$ \\
\hline $\begin{array}{l}\text { Son de maïs } \\
\text { Son de riz fin }\end{array}$ & 613 & 613 & 613 & 613 & 613 \\
Son de riz fort & 77 & 153 & 153 & 153 & 153 \\
Arachide broyée & 153 & 76,5 & 76,5 & 0 & 0 \\
$\begin{array}{l}\text { Farine de SP } \\
\text { de calmar }\end{array}$ & 0 & 0 & 76,5 & 0 & 153 \\
$\begin{array}{l}\text { Farine de SP } \\
\text { de poulpe }\end{array}$ & 0 & 76,5 & 0 & 153 & 0 \\
Sel & 4 & 4 & 4 & 4 & 4
\end{tabular}

* Remplacement de 50 ou $100 \%$ du tourteau d'arachide par des farines de SP de poulpe (P50, P100) ou de calmar (C50, C100)

$\mathrm{SP}$ : sous-produit 
avec des teneurs de 60,8 p. 100 pour les sous-produits de poulpe et de 52,1 p. 100 pour ceux de calmar. Introduites dans les aliments composés (tableau I), les farines des sous-produits de poulpe et de calmar ont permis un gain moyen de poids quotidien allant jusqu'à 17,4 g pour le lot P100. La figure 1 montre que le poids vif des poulets des cinq lots a varié, après 12 semaines d'expérience, en fonction de la nature et de la quantité des SPP utilisés, avec des valeurs atteignant $1943 \mathrm{~g}$ pour le lot P100 et 1614 g pour le lot C100, contre 1199 g pour le lot témoin.

Dans la ferme pilote de Saint Augustin, les bénéficiaires ont utilisé les sous-produits des poissons (figure 2). Le poids vif final de $1683 \mathrm{~g}$ pour les poulets nourris avec des aliments à base de la farine de sous-produits de poisson a été supérieur à celui du lot témoin.

Cette étude montre que les SPP, existant en quantité importante sur le littoral sud-ouest de Madagascar, peuvent être valorisés. Si Toliara abonde en SPP, essentiellement des sous-produits de poulpe et de calmar générés par les sociétés de pêche, Saint Augustin génère plutôt des SPP issus des ménages ou des restaurants. On estime par exemple que 200 tonnes par an de SPP sont générées par une société d'exportation des produits halieutiques basée à Toliara.

Le transfert des techniques de valorisation des SPP aux bénéficiaires a été réalisé à travers la mise en place d'une ferme pilote. Ceci permet de confirmer l'impact de l'étude dans le monde rural. Le développement de la filière avicole serait ainsi accueilli favorablement dans cette localité en tant qu'activité générant des revenus après la pêche. Au laboratoire, l'étude d'une voie de valorisation en alimentation piscicole a attiré l'attention de l'équipe en utilisant non seulement les farines des SPP mais aussi les hydrolysats des protéines des SPP.

Les auteurs remercient le Service de coopération et d'actions culturelles de l'ambassade de France à Madagascar pour l'appui financier du projet SPP.

\section{BIBLIOGRAPHIE}

1. ABDELMOULEH H., EL ABED A., BOUAIN A., 1998. Effet du produi fabriqué à base des déchets de seiche sur la croissance des poulets de chair. Bull. Inst. Nat. Sci. Technol. Mer (nº spécial) : 48-51.

2. FAO, 1986. The production of fish meal and fish oil. Rome, Italy, FAO, 63 p. (Fisheries technical papers $n^{\circ} 142$ )

Accepted 30 April 2015; Online publication June 2015

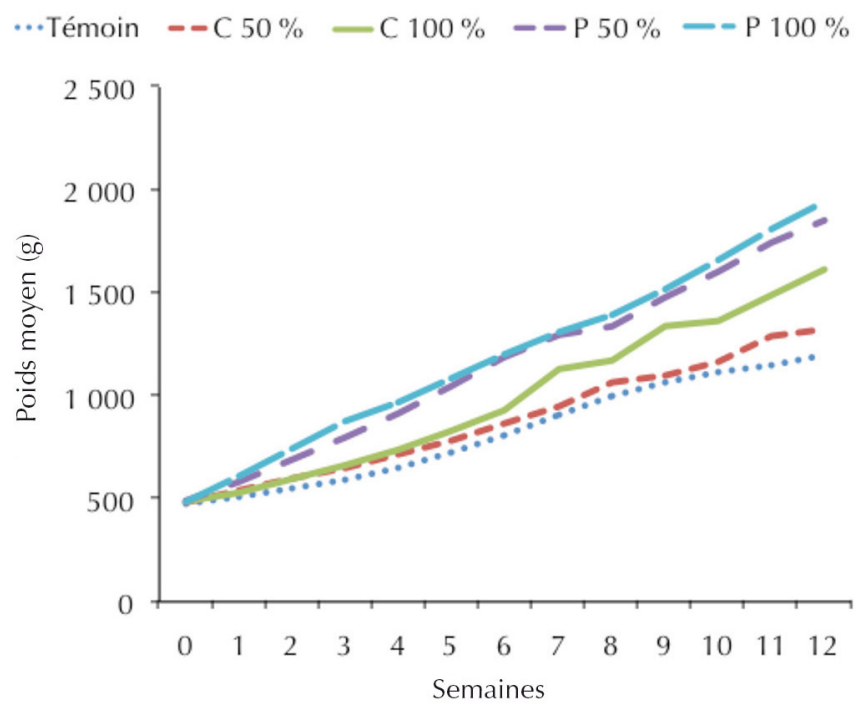

Figure 1 : croissance pondérale des cinq lots des poulets dans l'essai expérimental. $C$ : calamar ; $P$ : poulpe.

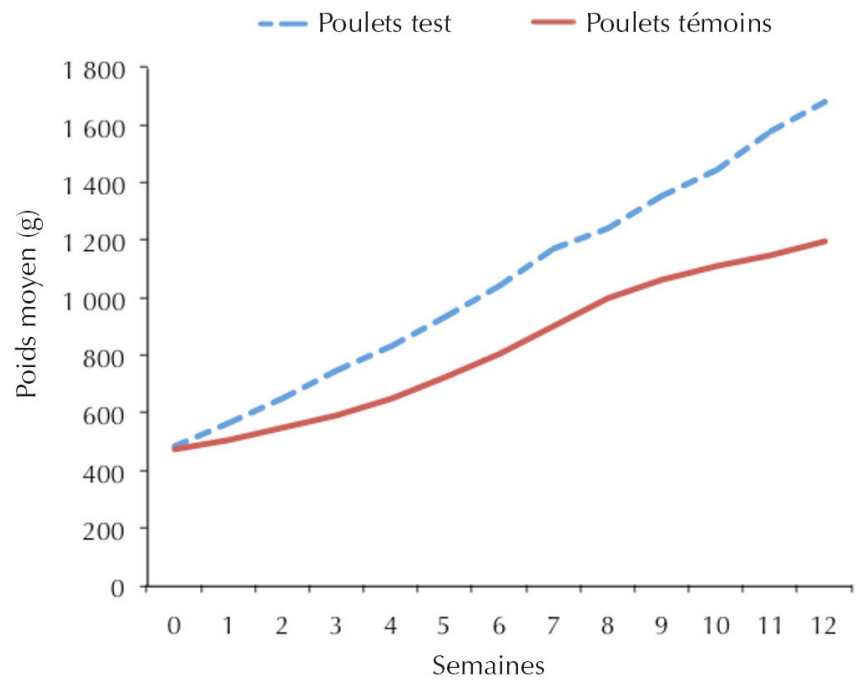

Figure 2: croissance pondérale des poulets lors de l'essai de terrain réalisé à la ferme pilote de Saint Augustin, Madagascar. 